\title{
Sequential Alterations in the Diameters of CAPILlaries in RabBit Skeletal Muscle FOLLOWING DEEP TRANSVERSE FRICTION - A MORPHOMETRIC STUDY
}

\begin{abstract}
Objective: The precise mechanisms by which massage promotes repair in injured soft tissue are unknown. Various authors have attributed the beneficial effects of massage to vasodilation and increased skin and muscle blood flow. The aim of this study was to determine whether deep transverse friction massage (DTF) causes capillary vasodilation in untraumatised skeletal muscle.

Setting: Academic institution.

Interventions: Twelve New Zealand white rabbits were anaesthetised and the left biceps femoris muscle received 10 minutes of DTF. Following treatment, wedge biopsies were taken from the muscle within 10 minutes of treatment (R1 - 4), 24 hours (R5 - 8) and 6 days (R9 - 12) after treatment. To serve as controls, similar biopsies were \section{Deane MN, BSc(Physio), MMedSc(Sports Med)'; Mars M, MBChB, MD}

Gregory MA, PhD';

${ }^{1}$ Emeritus Professor, Electron Microscopy Unit,

University of KwaZulu-Natal.

2 Lecturer, Department of Physiotherapy, University of KwaZulu-Natal.

${ }^{3}$ Professor and Head of the Department of

TeleHealth, Nelson R Mandela School of

Medicine, University of KwaZulu-Natal.

taken from the right biceps femoris of animals. The samples were fixed, dehydrated and embedded in epoxy resin. Transverse sections $(1 \mu \mathrm{m})$ of muscle were cut, stained with $1 \%$ aqueous alkaline toluidine blue and examined with a light microscope using a 40X objective. Images containing capillaries were captured using an image analyser with SIS software and the cross sectional diameters of at least 60 capillaries were measured from each specimen.

Main Outcome Measures: Changes in capillary diameter.

Results: The mean capillary diameters in control muscle averaged $4.76 \mu \mathrm{m}$. DTF caused a significant immediate increase of $17.3 \%$ in cross sectional area $(p<0.001)$, which was not significantly increased by $10.0 \%$ after 24 hours $(p>0.05)$. Six days after treatment the cross-sectional area of the treated muscle was $7.6 \%$ smaller than the controls. Conclusions: This confirms the contention that DTF stimulates muscle blood flow immediately after treatment and this may account for its beneficial effects in certain conditions.
\end{abstract}

\section{KEY WORDS: MASSAGE, BLOOD FLOW, CAPILLARY, LIGHT MICROSCOPY.}

\section{INTRODUCTION}

Massage is used to enhance the rate of repair, regeneration and recovery of skeletal muscles after injury or intense athletic activity (Cafarelli and Flint 2003, Smith et al 1994). When applied as a therapeutic intervention to treat soft tissue lesions, massage encourages damaged tissue to rapidly regain tensile strength and heal with a flexible, functional scar (Norris 1993). The precise mechanisms by which massage promotes such healing and repair are unknown. It has been proposed that certain types of massage may effect healing by increasing local blood flow (Goats 1994, Tiidus and Shoemaker 1995, Wyper and McNiven 1976). Improved muscle blood flow is thought to enhance the removal of metabolites such as lactate and hydrogen ions after exercise and the waste products of myofibre damage and or necrosis after injury, thereby improving recovery and healing rates (Tiidus and Shoemaker 1995).

Observations that gentle, manual massage dilates superficial blood vessels and increases the rate of blood flow were reported in the middle of the last century (Wilkins et al 1950), such dilation being deemed to be controlled by local axon reflexes (Severini and Venerando 1967). Forceful massage techniques such as deep effleurage are reported to increase both local blood flow and venous return, with a resultant increase in cardiac stroke volume and cardiac output (Goats 1994). Forceful massage applied to one limb has been reported to markedly increase blood flow in another, and this has been used to promote healing in a limb too sensitive for direct massage (Severini and Venerando 1967). A number of factors have been linked to massage induced vasodilation. These include local histamine release (Goats 1994), sympatho-

\section{CORRESPONDENCE TO:}

Professor Maurice Mars

Dept of TeleHealth

Nelson R Mandela School of Medicine

University of KwaZulu-Natal

Private Bag 7

Congella 4013

South Africa

Tel: $\quad 2731260-4364$

Fax: $\quad 2731260-4737$

Email: mars@ukzn.ac.za 
inhibition with involvement of the serotinergic pathway (Kaada and Eielsen 1983), increased serum concentrations of the vasoactive intestinal polypeptide (Kaada and Torstembo 1987), endothelium derived relaxing factor (Hester and Choi 2002), local nitric oxide release (Falcone and Bohlen 1990), and arachidonic acid derived metabolites such as prostacyclin and epoxyeicosatrienoic acids (Hammer et al 2001). There is little information on the duration of vasodilation produced by massage (Carrier 1922, Goats 1994).

Blood flow in muscle and skin has been measured in various ways. Clearance of an intramuscular injection of the radioisotope ${ }^{133}$ Xenon has been used to assess massage mediated changes in blood flow (Hansen and Kristensen 1973). Injection of ${ }^{133} \mathrm{Xe}$ for the clearance test does however cause local hyperaemia, which may result in an overestimation of blood flow values (Marcus et al 1981). Echo and pulsed Doppler techniques have been used to measure arterial diameter and erythrocyte velocity in limb muscles (Chauveau et al 1985, Shoemaker et al 1997, Tiidus and Shoemaker 1995, Tschakovsky et al 1995). Although particularly useful as a non-invasive means of measuring total arterial blood flow through sub-dermal tissues, the Doppler methodology is not able to determine changes of perfusion at the microvascular level within muscle. Laser Doppler fluxmetry and transcutaneous oxygen pressure measurement are effective ways of evaluating skin blood flow, but both have methodological limitations (Mars et al 1993, Mars et al 1998).

Another approach to determining changes in vasodilation in muscle is by direct measurement of the cross sectional diameter of capillaries between muscle bundles. While this invasive method of estimating changes in blood flow is generally reserved for studies using animals, there are a number of reports describing capillary statistics in the normal (Gidlof et al 1987a) and pathological skeletal muscle of man (Jerusalem et al 1974, Kretschmar and Engelhardt 1994). Most experimental studies, however, centre on changes in capillary diameters and luminal cross-sectional areas after ischaemia and reperfusion (Egginton et al 1993, Gidlof et al 1987b, Mars 2002). Our group has previously reported the use of morphometric analysis of capillary diameter to determine the effect of a single episode of compressed air massage on skeletal muscle blood flow (Gregory and Mars 2003). A possible limitation of this technique is that not all capillaries are open at any given moment in resting skeletal muscle. If treatment were to cause more capillaries to occlude, the residual patent capillaries might be dilated without any increase in total volume blood flow.

While numerous studies suggest that massage, and deep effleurage in particular, promote soft-tissue healing by improving blood flow to the affected area, there are no studies that unequivocally demonstrate this. Further, the duration of vasodilation produced by different forms of massage has not been reported. In a recent study, this group reported that following a single 10 minute massage with compressed air, the cross-sectional diameters of capillaries in rabbit vastus lateralis muscle increased by $7.5 \%$ immediately after treatment $(\mathrm{p}<0.05$ ) increasing to $10.4 \%$, 24 hours later $(\mathrm{p}<0.05)$. Six days after compressed air massage capillary diameters had returned to control values (Gregory and Mars 2003).

We have previously reported the effect of deep transverse friction (DTF) on the morphology of rabbit biceps femoris myofibres (Gregory et al 2003). Having noted a difference in the response of skeletal muscle to DTF and compressed air therapy (Gregory and Mars 2004), the possibility exists that there may also be a difference in the vasodilatory response of the capillaries to DTF. As the muscle biopsies after DTF and compressed air massage had been obtained at similar times (within 10 minutes of treatment and 24 hours and 6 days after treatment) and as the tissue for both studies had been fixed, prepared and embedded in resin in precisely the same manner, it is possible to re-examine the DTF biopsies looking specifically at the capillary morphometry and to compare the results with compressed air massage. The only difference in study protocols was in the control biopsies. In the com- pressed air study, control biopsies were taken from the untreated leg of each animal whereas in the DTF study control biopsies were only taken from the animals biopsied 6 days after DTF.

This study examines the effect of DTF on skeletal muscle vasodilation using capillary morphometry and compares the results with capillary vasodilation following compressed air massage.

\section{METHODS}

Twelve New Zealand, white rabbits were studied with the approval of the Ethics and Research Committees of the University of Natal and the University of Durban-Westville. The animals were housed in the Biomedical Resource Centre (BRC) of the University of Durban Westville and were maintained under the care of the staff of the BRC. The animals were fed ad libitum. Before DTF, anaesthesia and analgesia were achieved by an intramuscular injection of a combination of $50 \%$ Ketamine and $50 \%$ Xylazine, $10 \mathrm{mg} / \mathrm{kg}$ of rabbit body weight.

\section{Muscle Biopsy and Preparation}

The treatment area was at the level of the mid-thigh. The fur was removed with a depilatory to enable observation of any inflammatory reaction and to facilitate treatment. To ensure that biopsies were obtained from the correct position, the treatment site was clearly marked with indelible ink. Treatment consisted of a single, 10 minute episode of deep transverse friction, using the index finger (MD). After DTF, the animals were observed during recovery from the anaesthetic and then returned to the holding facility.

Open wedge muscle biopsies were obtained from the left biceps femoris within 10 minutes of DTF (R1 - R4) and under anaesthetic 24 hours (R5 - R8) and 6 days after DTF (R9 -12). Biopsies were taken from the right biceps femoris of animals 9 - 12 (RC9 - RC12) to serve as controls. Muscle biopsy consisted of longitudinal incision of the skin and fascia over the treatment site and excision of a wedge biopsy of approximately $1 \mathrm{~cm}^{3}$.

To reduce biopsy induced, muscle "supercontraction" artefact which might have an effect on inter-muscle bundle 
capillary dimensions, the entire biopsy was immediately immersed in Karnovsky's fixative (Karnovsky 1965) as per the method of Olmesdahl (Olmesdahl et al 1979). After 5 minutes immersion, the biopsy was examined with a stereomicroscope to determine the alignment of myofibres. To facilitate orientation during the processing and embedding procedures, blocks of tissue approximately $1 \mathrm{~mm} \mathrm{X} 2 \mathrm{~mm}$ were excised from the biopsy in such a way that the greater dimension followed the longitudinal axis of myofibres in muscle bundles. The rectangular blocks were re-immersed in Karnovsky's fixative for a further hour, washed in $0.2 \mathrm{M}$ cacodylate buffer, post-fixed in $1 \%$ osmium tetroxide, dehydrated through graded ethanols and following perfusion with Spurr's epoxy resin (Spurr 1969), longitudinally orientated and "flat" embedded in silicone moulds. Sections of $1 \mu \mathrm{m}$ were cut of the transversely orientated myofibres using glass knives and stained with $1 \%$ aqueous alkaline toluidine blue.

The sections were examined using a Reichert light microscope with a X40 objective and the external cross-sectional diameter of capillaries measured using an image analyser and SIS software. The morphometric method employed was based on the "mean diameter method" described by Dubowitz in 1968 (Dubowitz 1985, Spurr 1969). When muscle is transversely sectioned, most capillaries in muscle bundles are also cross or obliquely sectioned. Although few capillaries were completely circular, they were considered to be near cylinders and their diameters taken to be the external minimum distance across each structure. A minimum of 60 capillaries were measured from each control and experimental specimen. The mean, standard deviation, and error of the mean were determined for the capillaries within each animal and for each group of animals. The distributions of capillary diameters in each group of specimens were expressed as frequency polygons. Comparisons of means within and between groups were by analysis of variance using the Kruskal-Wallace ANOVA with post-hoc testing using Dunn's test. The alpha level was set at $5 \%$.

\section{RESULTS}

Prior to DTF massage, the average weight of rabbits was $2.74 \pm 0.34 \mathrm{~kg}$. No changes in weight of the animals was noted between treatment and biopsy. There was obvious ecchymosis of the skin during, immediately after and 24 hours after DTF. The inflammation disappeared within 48 hours of massage. Following DTF, there was considerable hyperaemia with bleeding in all biopsies taken within 10 minutes of treatment. No hyperaemia was noted 24 hours or

Table 1:The capillary diameters $(\mu \mathrm{m})$ and cross sectional areas $\left(\mu \mathrm{m}^{2}\right)$ of the control and DTF treated groups are expressed as means, one standard deviation and the $95 \%$ confidence interval $(95 \% \mathrm{Cl})$. The percentage change from the control group is given ( $\%$ Change). The statistical significance of the change between the control group and the treated groups is shown (p).

\begin{tabular}{|l|l|l|l|l|}
\hline & \multicolumn{1}{|c|}{ Control } & \multicolumn{1}{|c|}{$<\mathbf{1 0}$ Min } & \multicolumn{1}{|c|}{$\mathbf{2 4}$ Hours } & \multicolumn{1}{c|}{ Days } \\
\hline $\mathrm{N}=$ & 343 & 272 & 429 & 412 \\
\hline Diameter $(\mu \mathrm{m})$ & $4.76(1.28)$ & $5.18(1.32)$ & $4.97(1.43)$ & $4.60(1.13)$ \\
\hline $95 \% \mathrm{Cl}$ & $4.63-4.90$ & $5.02-5.33$ & $4.84-5.11$ & $4.49-4.71$ \\
\hline$\% \mathrm{Change}$ & & 8.7 & 4.4 & -3.4 \\
\hline Area $\left(\mu \mathrm{m}^{2}\right)$ & $19.11(11.81)$ & $22.42(13.01)$ & $21.03(14.56)$ & $17.65(10.48)$ \\
\hline $95 \% \mathrm{Cl}$ & $17.86-20.36$ & $20.87-23.97$ & $19.65-22.41$ & $16.64-18.66$ \\
\hline$\% \mathrm{Change}$ & & 17.3 & 10.0 & -7.6 \\
\hline$p$ & & $<0.001$ & $>0.05$ & $>0.05$ \\
\hline
\end{tabular}

Figure 1: Light micrograph showing cross-sectioned capillaries and measurement positions, 40X magnification. ( $F=$ myofibre, $C=$ Capillary).

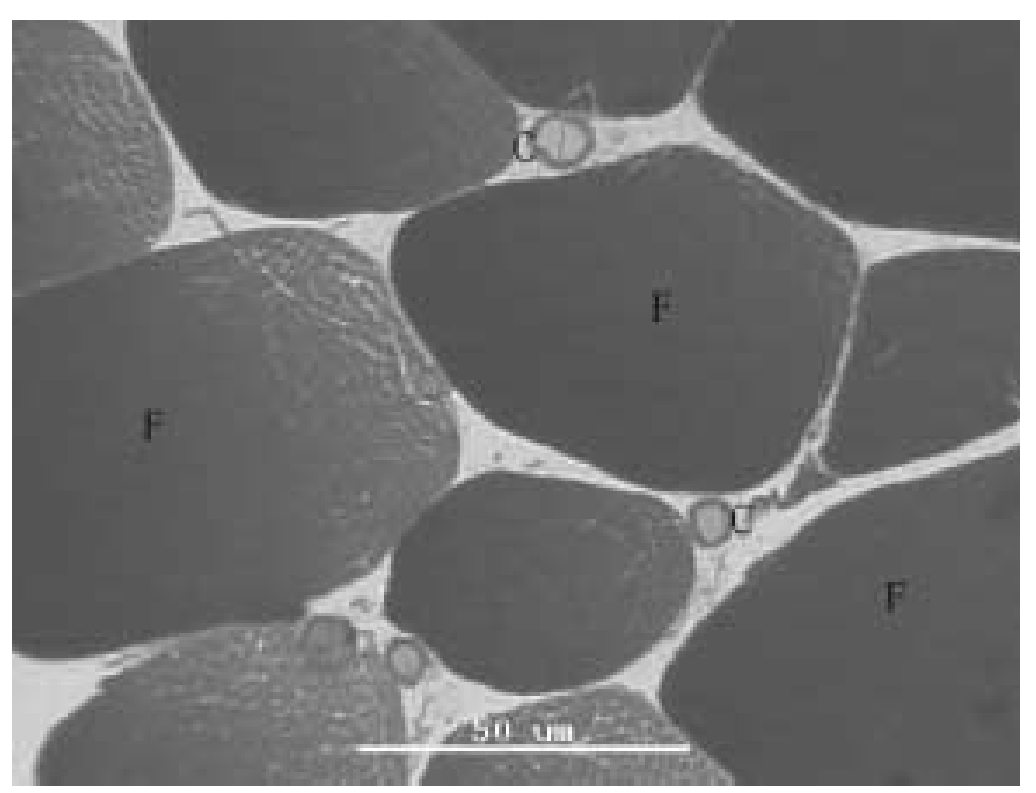


Figure 2: Frequency distribution $(\%)$ of capillary diameters $(\mu \mathrm{m})$ in control muscle and muscle 10 minutes, 24 hours and 6 days after treatment.

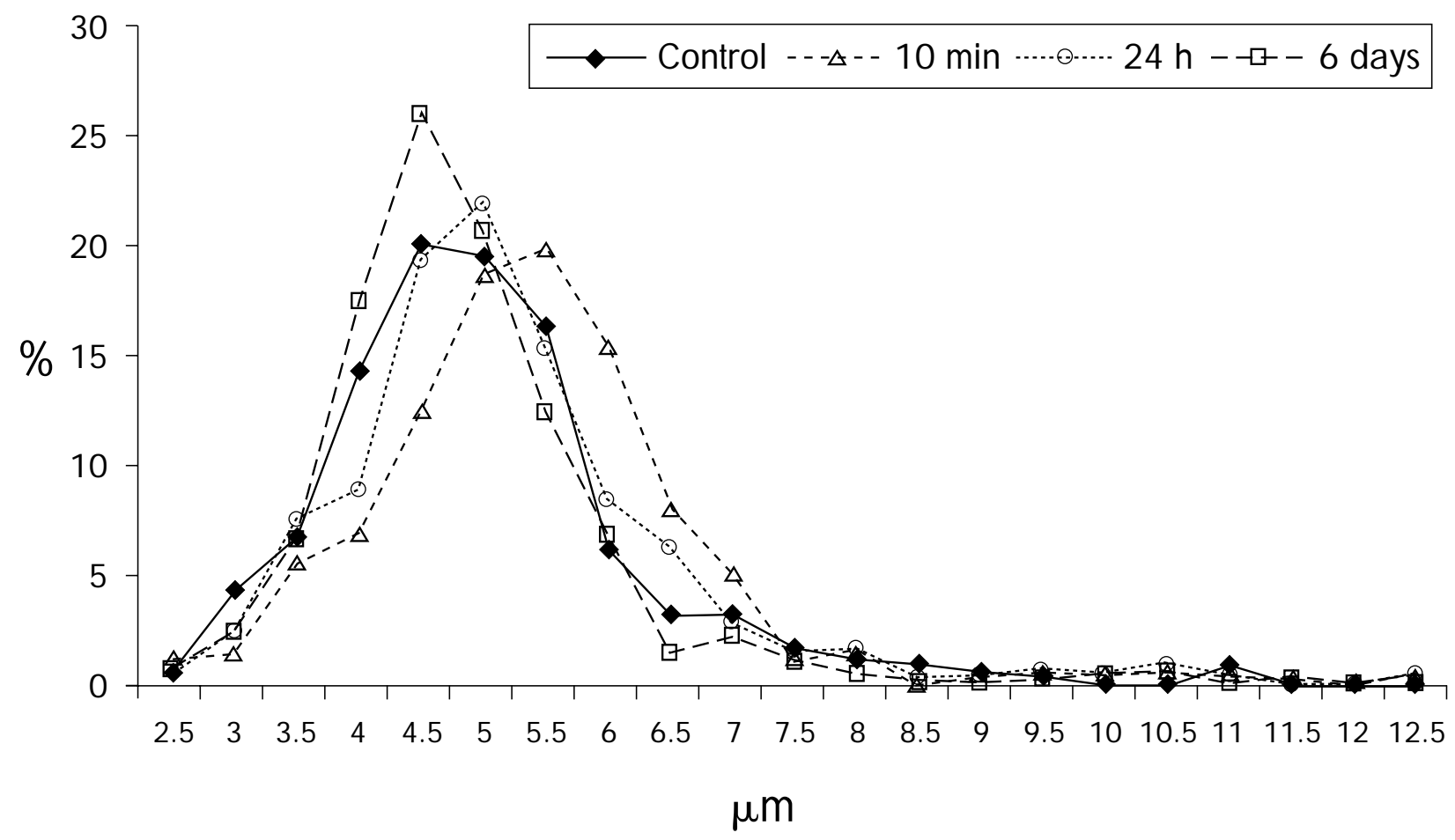

Figure 3: Percentage change in the cross-sectional area of capillaries after DTF or compressed air massage.

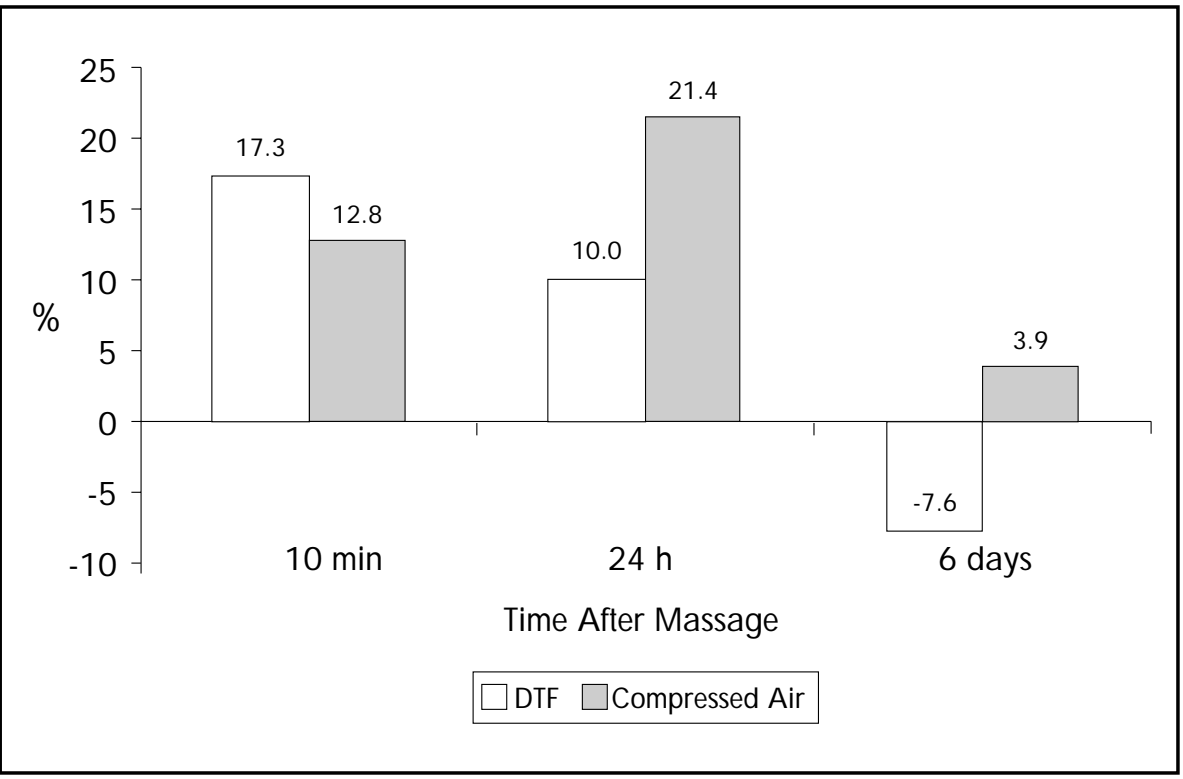

trol muscle was $4.76 \pm 1.28 \mu \mathrm{m}$ with a cross-sectional area of $17.8 \mu \mathrm{m}^{2}$. Within 10 minutes of DTF massage, mean cross-sectional diameter had increased by $8.7 \%$ to $5.18 \pm 1.32 \mu \mathrm{m}(\mathrm{p}<0.001)$ and cross-sectional area had increased by $17.31 \%$ to $22.42 \pm 13.01 \mu \mathrm{m}^{2}$. Twentyfour hours after treatment mean crosssectional diameter was $4.97 \pm 1.43 \mu \mathrm{m}$ (an increase of $4.4 \%$ ) with a mean crosssectional area of $19.65+22.41 \mu \mathrm{m}^{2}$ (an increase of $10 \%, \mathrm{p}>0.05)$. Six days after treatment, although capillaries were on average smaller $4.60 \pm 1.13 \mu \mathrm{m}$, the mean cross-sectional area of capillaries in massaged muscle of $17.65 \mu \mathrm{m}^{2}$ was not significantly different to that of control muscle.
The frequency distributions of capillaries are shown in Figure 2. Within a range of $2.0 \mu \mathrm{m}$ and $12.5 \mu \mathrm{m}$ there is a normal distribution of cross sectional diameters in control specimens, with the mode at the range $4.0-4.5 \mu \mathrm{m}(20.1 \%)$. Within 10 minutes of massage, the distribution is shifted to larger diameters with the mode in the range $5.0-5.5 \mu \mathrm{m}$ (19.9\%). Twenty-four hours after treatment the distribution indicates a return towards the control distribution with the mode in the range $4.5-5.0 \mu \mathrm{m}$ $(21.9 \%)$. Six days after treatment, the distribution is similar to that of the control specimens with the mode in the range $4.0-4.5 \mu \mathrm{m}(26.0 \%)$. Maximum capillary diameter increased from $10.94 \mu \mathrm{m}$ in control muscle to $12.47 \mu \mathrm{m}$ 24 hours after treatment.

The pattern of vasodilation after DTF is shown in Figure 3 and the changes in cross-sectional area after compressed air therapy, reported in an earlier study, are included for comparison. After DTF there was a significant initial increase in cross-sectional area which was nonsignificantly increased after 24 hours and which returned to sub-normal values over the 6 day period. Following com- 
pressed air massage there was a significant initial moderate increase in the cross-sectional area of capillaries which increased further at 24 hours after treatment, before returning to normal values 6 days after treatment.

\section{DISCUSSION}

Having recently established that compressed air therapy causes sustained vasodilation in untraumatised skeletal muscle (Gregory and Mars 2003), the primary objectives of this study were to determine whether another, more common type of deep effleurage massage, deep transverse friction also causes skeletal muscle capillaries to dilate and if so, whether the duration of vasodilation differed with treatment modality. Deep transverse friction, popularised by Cyriax and Russel in the 1970's (Cyriax and Russel 1977) and later reviewed by Chamberlain, is a massage technique that has been advocated for the treatment of muscle strains and tears, tenosynovitis, tendonitis and ligament strains ( Chamberlain 1982, Fritschy and de Gautard 1988, Gimblett et al 1999, Hammer 1993). The DTF technique provides therapeutic movement over a small area thereby enabling pressure to be applied to greater depth in muscle. According to Norris, this promotes local hyperaemia, with the increased blood supply helping to accelerate healing, reduce adherent scar tissue and induce massage analgesia (Norris 1993).

The findings of this study support the contention that DTF increases capillary blood flow in skeletal muscle. Based on changes in cross sectional area, vasodilation after DTF was maximal within 10 minutes of treatment $(17.3 \%)$, with reduced dilation present at 24 hours (10\%). The cross sectional area was non-significantly reduced by $(7.6 \%)$ 6 days after treatment. The presence of capillary dilation was further supported by the marginal distribution data. Within 10 minutes of treatment, the marginal distribution of capillary diameters showed a general shift to larger diameters with the mode increasing from the range $4.0-4.5 \mu \mathrm{m}(20.1 \%)$ to the range $5.0-5.5 \mu \mathrm{m}(19.9 \%)$. Twenty-four hours after treatment, the mode occurred in the range $4.5-5.0 \mu \mathrm{m}(21.9 \%)$ with the capillary diameters appearing to be returning to control values. Six days after $\mathrm{DTF}$, the mode returned to the range $4.0-4.5 \mu \mathrm{m}(26.0 \%)$ with the average capillary area $7.7 \%$ less than controls, with a reduction in larger diameter fibres.

Compressed air therapy is a new form of massage treatment that uses air under compression of 1 - 1.5 Bar to massage skin and underlying soft tissue. The pressure of the air jet is transmitted to the subcutaneous tissues and it can therefore be considered to be a deep effleurage treatment similar to deep transverse friction. The reported response of skeletal muscle capillaries to compressed air therapy is somewhat different. Within 10 minutes of compressed air treatment, capillary cross-sectional area increased by $13 \%$ ( $\mathrm{p}<0.001)$. Twentyfour hours later, further vasodilation was noted with the mean cross sectional area $21 \%$ greater than the controls $(\mathrm{p}<0.001)$. By six days after treatment the compressed air treatment still showed a non significant increase in area of $4 \%$ (Gregory and Mars 2003).

These data show that both deep effleurage treatments cause an increase in capillary cross-sectional area. There is however a difference in the degree and duration of vasodilation. Deep transverse friction resulted in an immediate maximal increase in capillary diameters while compressed air therapy resulted in an increase in capillary diameter that was more sustained and maximal 24 hours after treatment. Six days after treatment, although not statistically significant, there was a trend for relative vasoconstriction in capillaries in muscle that had undergone DTF.

There are several possible factors which may account for the difference in the time related pattern of change in capillary size. Using light microscopy, it is difficult if not impossible to identify and differentiate between blood and lymph capillaries. Lymphatic capillaries are reported to be larger than those carrying blood (Bloom and Fawcett 1968). The larger mean diameter of capillaries following DTF and compressed air massage may be a reflection of improved lymphatic perfusion. The increase in capillary diameters seen 24 hours after compressed air massage may be indicative of preferential dilatation of lymphatic capillaries after this massage modality, secondary to increased tissue damage.

The difference in the pattern and duration of capillary dilatation may be a consequence of differences in the massage techniques. DTF consists of localised and sustained pressure application. With compressed air therapy the applied pressure is dispersed over a wider area as the applicator head is moved over the skin and underlying muscle. This will result in a lower dose of pressure per square unit area of tissue receiving compressed air massage. Sustained local pressure is more likely to cause muscle damage than dispersed pressure. This is supported by the observations that the pattern of muscle injury caused by DTF is more severe than that caused by compressed air. Within 10 min of DTF treatment, focal areas of supercontraction containing areas of disorganised actin and myosin were seen. Two forms of inclusion bodies were noted 24 hours later. Some fibres had multi-lobed nuclei and mitochondrial abnormalities were noted. Six days after treatment the majority of fibres were normal with abnormal fibres containing internalised nuclei together with inclusions and large aggregates of disorganised myofilaments. In some fibres, large tracts of the sarcosol had lost their complement of contractile elements (Gregory et al 2003). After compressed air massage the most consistent change was juxta-nuclear and intermyofibrillar oedema with generally normal mitochondria and t-tubules. After 24 hours there was less oedema, peripheral $\mathrm{Z}$ band streaming was noted in some fibres and occasional focal supercontracted sarcomeres were seen. Six days after treatment very occasional $\mathrm{Z}$ band streaming and some internalised nuclei were seen. No inclusion bodies were seen in muscle after compressed air massage (Gregory and Mars 2004).

The differences in capillary dilation and muscle injury may also be secondary to temperature differences. DTF is associated with an increase in skin and possibly muscle temperature due to friction. Compressed air treatment in contrast cools both skin and muscle. Cooling is the result of expansion of 
compressed air as it is released from the applicator head. Skin is cooled by about $5{ }^{\circ} \mathrm{C}$ and this persists for up to 15 minutes after treatment (Mars 2003). Cooling would be expected to be associated with vasoconstriction and the dilation noted 10 minutes after treatment may be evidence of reactive hyperaemia associated with warming. Cooling is also known to slow cellular metabolism and this may offer some protection to the muscle from the pressure damage caused during massage.

This light microscopy study confirms that DTF causes skeletal muscle capillary vasodilation within 10 minutes of treatment with non-significant vasodilation still present 24 hours after treatment. This supports the contention that DTF acts through the promotion of soft tissue hyperaemia. The pattern and duration of vasodilation noted is different to that seen after a new form of pressure massage using compressed air. Further work is required to quantify the pressures transmitted to muscle during DTF and to determine if compressed air massage is a less traumatic alternative to DTF.

\section{REFERENCES}

Bloom A, Fawcett B 1968 A textbook of histology $9^{\text {th }}$ ed. p:390. W.B. Saunder and Co, Philadelphia

Cafarelli E, Flint F 2003 The role of massage in preparation for and recovery from exercise. Sports Medicine 14:1-9

Carrier EB 1922 Studies on the physiology of capillaries. The reaction of human skin capillaries to drugs and other stimuli. American Journal of Physiology 61:528-547

Chamberlain GL 1982 Cyriax's friction massage: a review. Journal of Orthopaedic Sports Physical Therapy 4:16-22

Chauveau M, Levy B, Dessanges JF, Savin E, Bailliart O, Martineaud JP 1985 Quantitive Doppler blood flow measurement method and in-vitro calibration. Cardiovascular Research 19:700-706

Cyriax J, Russel G 1977 Treatment by manipulation massage and injection. In: Textbook of orthopaedic medicine 6th ed, pp 18-36. Williams and Williams, Baltimore

Dubowitz V 1985 Normal Muscle. In: Dubowitz V, Seewry CA, Fitzsimons RB (ed) Muscle biopsy a practical approach, pp 82-128 Bailliere and Tindall, London
Egginton S, Hudlicka O, Glover M 1993 Fine structure of capillaries in ischaemic and non-ischaemic rat striated muscle. Effect of torbafylline. International Journal of Microcirculation and Clinical Experimentation $12: 33-44$

Falcone JC, Bohlen HG 1990 EDRF from rat intestine and skeletal muscle venules causes dilation of arterioles. American Journal of Physiology 258:H1515-H1523

Fritschy D, de Gautard R 1988 Jumper's knee and ultrasonography. American Journal of Sports Medicine 16:637-640

Gidlof A, Lewis DH, Hammersen F 1987a Fine structure of human skeletal muscle capillary. A morphometric analysis. Journal of Microcirculation Clinical and Experimental 7:43-66

Gidlof A, Lewis DH, Hammersen F 1987b The effect of prolonged total ischaemia on the ultrastructure of human skeletal muscle capillaries. A morphometric analysis. International Journal of Microcirculation: Clinical and Experimental 7:67-86

Gimblett PA, Saville J, Ebrall P 1999 A conservative management protocol for calcific tendinitis of the shoulder. Journal of Manipulative and Physiological Therapeutics 22:622-627

Goats GC 1994 The scientific basis of an ancient art: Part 2. Physiological and therapeutic effects. British Journal of Sports Medicine 28:153-156

Gregory MA, Deane MN, Mars M 2003 Ultrastructural changes in untraumatised rabbit skeletal muscle treated with deep transverse friction. Physiotherapy 89:408-416

Gregory MA, Mars M 2003 A morphometric and ultrastructural evaluation of capillaries in rabbit vastus lateralis muscle before and after compressed air massage. Microscopy and Microanalysis 9:1438-1439

Gregory MA, Mars M 2004 The effect of compressed air massage on untraumatised rabbit skeletal muscle - a morphometric and ultrastructural study. South African Journal of Physiotherapy 60:19-27

Hammer LW, Ligon AL, Hester RL 2001 ATP-mediated release of arachidonic acid metabolites from venular endothelium causes arteriolar dilatation. American Journal of Physiology 280:H2616-H2622

Hammer WI 1993 The use of transverse friction massage in the management of chronic bursitis of the hip or shoulder. Journal of Manipulative and Physiological Therapeutics 16:107-111

Hansen TI, Kristensen JH 1973 Effect of massage short-wave diathermy and ultrasound upon 133Xe disappearance rate from muscle and subcutaneous tissue in the calf. Scandinavian Journal of Rehabilitation Medicine 5:179-182
Hester RL, Choi J 2002 Blood flow control during exercise: role for the venular endothelium? Exercise and Sport Sciences Reviews 30:147-151

Jerusalem F, Rakusa M, Enggel AG, McDonald RD 1974 Morphometric analysis of skeletal muscle capillary ultrastructure in inflammatory myopathies. Journal of Neorological Science 23:391-402

Kaada B, Eielsen O 1983 In search of mediators of skin vasodilation induced by transcutaneous nerve stimulation: II. Serotonin implicated. General Pharmacology 14:635-641

Kaada B, Torstembo O 1987 Vasoactive intestinal polypeptides in connective tissue massage. General Pharmacology 18:379-384

Karnovsky MJ 1965 A formaldehyde glutaraldehyde fixative of high osmolarity for use in electron microscopy. Journal of Cell Biology 27:127-139

Kretschmar K, Engelhardt TH 1994 Swelling of capillary endothelial cells contribute to traumatic hemorrhagic shock-induced microvascular injury: A morphologic and morphometric analysis. International Journal of Microcirculation: Clinical and Experimental 14:45-49

Marcus ML, Bischoff CJ, Heistad DD 1981 Comparison of microsphere and xenon-133 clearance method in measuring skeletal muscle and cerebral blood-flow. Circulation Research 48:748-761

Mars M 2002 Jet therapy - its effect on skin blood flow, muscle pressure and blood parameters. South African Journal of Surgery 40:23-

Mars M 2003 Compressed air massage, a new treatment modality? Medicine and Science in Sports and Exercise 35:S92-

Mars M, McKune A, Robbs JV 1998 A comparison of laser Doppler fluxmetry and transcutaneous oxygen pressure measurement in the dysvascular patient requiring amputation. European Journal of Vascular and Endovascular Surgery 16:53-58

Mars M, Mills RP, Robbs JV 1993 The potential benefit of pre-operative assessment of amputation wound healing potential in peripheral vascular disease. South African Medical Journal 83:16-18

Norris C 1993 Sports Injuries. Sports Injuries pp 109-111. Butterworth Heineman, New York

Olmesdahl PJ, Gregory MA, Cameron EWJ 1979 Ultrastructural artefacts in biopsied normal myocardial biopsy in man. Thorax 34:82-90

Severini V, Venerando A 1967 Effect on the peripheral circulation of substances producing hyperaemia in combination with massage. Europa Medicophysica 3:184-198 
Shoemaker JK, Tiidus PM, Mader R 1997 Failure of manual massage to alter limb blood flow: measures by Doppler ultrasound. Medicine and Science in Sports and Exercise 29:610-617

Smith LL, Keating MN, Holbert D, Spratt DJ, McCammon MR, Smith SS, Israel RG 1994 The effects of athletic massage on delayed onset muscle soreness, creatine kinase and neutrophil count: A preliminary report. JOSPT: The Journal of Orthopaedic and Sports Physical Therapy 19:93-99
Spurr A 1969 A low viscosity epoxy resin embedding medium for electron microscopy. Journal of Ultrastructure Research 26:31-43

Tiidus PM, Shoemaker JK 1995 Effleurage massage, muscle blood flow and long-term post-exercise strength recovery. International Journal of Sports Medicine 16:478-483

Tschakovsky ME, Shoemaker JK, Hughson RL 1995 Beat-by-beat forearm blood flow with Doppler ultrasound and strain gauge plethysmography. Journal of Applied Physiology 79:713-719
Wilkins RW, Halperin MH, Litter J 1950 The effects of various physical procedures on circulation in human limbs. Annals of Internal Medicine 33:1232-1245

Wyper DJ, McNiven DR 1976 Effects of some physiotherapeutic agents on skeletal muscle blood flow. Physiotherapy 62:83-85

\title{
Motor Recovery Profile of Stroke Patients AdmitTed to A REHABILITATION HoSPITAL IN KUWAIT
}

\begin{abstract}
Aims: To describe the pattern of clinical presentation and motor recovery of male stroke survivors as seen in a rehabilitation facility in Kuwait.

Methods: Thirty patients with first stroke that satisfied the inclusion criteria were studied retrospectively. Patients received a multidisciplinary care, and the Physiotherapy component was about one hour daily, five times in a week. Motor impairment was assessed at admission and discharge using the Chedoke-McMaster Stroke Assessment scale. Demographic and clinical information were also documented.

Results: About a quarter of the total admissions during the study period were stroke cases. The mean age of the patients was 59.10 years. Cerebral infarction was the cause of stroke in $75.9 \%$ of the patients. Hypertension was the commonest risk factor, but patients had multiple risk factors. Mean length of hospital stay (LOS) and onset of stroke to admission (On-adm.) were 76.03 and 45.53 days respectively. Discharge motor impairment was significantly better than admission scores ( $p<0.05)$. On-adm. time influenced only the upper limb motor score at discharge ( $p<0.05)$, and comparison of the On-adm. groups showed a significant difference between patients admitted within first month of stroke and after two months.

Conclusion: Stroke is a common neurological condition admitted for rehabilitation in Kuwait. Clinical presentation was similar to those reported from neighbouring gulf countries. Stroke patients in this study had significant improvement of motor impairment at discharge. Patients with early admission, tended to have better upper limb motor score at discharge.
\end{abstract}

